University of Windsor

Scholarship at UWindsor

1995

\title{
The association of near poverty status with cancer incidence among black and white adults
}

Kevin M. Gorey

University of Windsor

Follow this and additional works at: https://scholar.uwindsor.ca/socialworkpub

Part of the Epidemiology Commons, and the Social Work Commons

\section{Recommended Citation}

Gorey, Kevin M.. (1995). The association of near poverty status with cancer incidence among black and white adults. Journal of Community Health, 20 (4), 359-366.

https://scholar.uwindsor.ca/socialworkpub/24

This Article is brought to you for free and open access by the School of Social Work at Scholarship at UWindsor. It has been accepted for inclusion in Social Work Publications by an authorized administrator of Scholarship at UWindsor. For more information, please contact scholarship@uwindsor.ca. 


\title{
THE ASSOCIATION OF NEAR POVERTY STATUS WITH CANCER INCIDENCE AMONG BLACK AND WHITE ADULTS
}

\author{
Kevin M. Gorey, PhD, MSW and John E. Vena, PhD
}

\begin{abstract}
This cumulative incidence study was accomplished among adults in Upstate New York metropolitan areas (Buffalo, Rochester, Syracuse and Albany-1979-1986). It used a new ecological socioeconomic status measure-near poverty status (i.e., below $200 \%$ of the federally established poverty criterion, including the poor and near poor)-and observed its association with site-specific cancer incidence (lung, stomach, cervix uteri, prostate, colon, rectum and breast). Findings were: 1) near poverty status is directly associated with each cancer site's incidence and the strength of the associations are similar among blacks and whites for each one and 2) the prevalence of exposure, of living in high near impoverishment areas, is nearly seven-fold greater among blacks; prevalence ratio $[P R]=6.74(95 \%$ confidence interval $[C I]: 5.07,8.99)$.
\end{abstract}

\section{INTRODUCTION}

Racial group disparities which are consistent with relative black disadvantage on cancer incidence, mortality and survival have been observed in the United States for all sites combined as well as for many specific cancer sites. The known sociodemography of the U.S. has implicated socioeconomic status (SES) differences as a salient explanation for these between-racial group cancer differentials. Because of the complete lack of information relevant to SES represented among data bases of populationbased tumor registries, all of the studies in this field are ecological with respect to socioeconomic exposure measurement. Aggregate SES mea-

Kevin M. Gorey, PhD, is Assistant Professor, School of Social Work, University of Windsor, 401 Sunset, Windsor, Ontario, N9B 3P4, CANADA; John E. Vena, PhD is Associate Chair and Associate Professor, Department of Social and Preventive Medicine, School of Medicine and Biomedical Sciences, State University of New York at Buffalo, 3435 Main Street, Farber Hall, Rm 270, Buffalo, NY, 14214, USA.

This work was supported by Grant No. CA09051-17 from the National Cancer Instituce. The authors gratefully acknowledge the assistance provided by Drs. Nancy Kricger (Kaiser Foundation Research Institute, Oakland, CA), Richard G. Wilkinson (University of Sussex at Brighton, England), Maria A. Zielezny (Department of Social and Preventive Medicine, University at Buffalo) and Arthur M. Michalek (Education and Epidemiology Departments, Roswell Park Cancer Institute, Buffalo, NY) who critically reviewed earlier draft versions of this manuscript. The administrative assistance provided by the director of New York State's (NYS) Cancer Registry, Dr. Mark S. Baptiste (Bureau of Cancer Epidemiology, NYS Department of Health), is also gratefully acknowledged.

Requests for reprinus should be addressed to: Dr. Kevin M. Gorey, School of Social Work, University of Windsor, 401 Sunset Avenue, Win \$sor, Ontario N98 3P4, Canada.

1995 Human Sciences Press, Inc. 
sures, based upon geographic areas such as census tracts, have been used to characterize the individual's exposure: The vast majority of this extant research $(90 \%)$ has focused upon income central tendency (e.g., census tract median income or some more complex measure which includes median income) and found it for example to be inversely associated with cancer incidence among both blacks and whites for sites with demonstrated greater incidence among blacks such as lung, stomach and cervix uteri. ${ }^{1.2}$

We concur with others who have recently cautioned against necessarily viewing ecological inferences as suspect and individual ones correct, ${ }^{34}$ and we do not assume that ecological models are substitutes for individuallevel ones. The above described body of research, which reviews more than 300 studies in this field, provides the means for making contextual inferences concerning the nature of underlying neighborhood living circumstances, thus, making a valuable contribution to our understanding of cancer occurrence and potential avenues for prevention, notwithstanding that of individual-level study. ${ }^{3.7}$ The following question may be asked of these previous ecological studies however: How much of the context in which people live or the socioeconomic environment have they accounted for in typically using only one data point to describe an economic distribution, for example, the median income to describe the incomes of approximately 4,000 people in a census tract? International studies of all-cause mortality have emphasized the dispersion and shape of economic distributions a la socioeconomic inequality or relative deprivation. ${ }^{8-12}$ Perhaps the best analog for census/cancer registry based study is prevalent impoverishment. Only two studies in this field have incorporated poverty status in their designs, and none have used the more liberal poverty criterion which this study does.

\section{METHODS}

The New York State (NYS) Cancer Registry provided access to data on the following cancer sites for this study: lung, stomach. cervix uteri, prostate, colon, rectum and breast. Among black or white adults, 41,978 such cases arose in Upstate NY metropolitan areas from 1979 to 1986 (1979-first year geocodes, based upon residence at the time of diagnosis, were accomplished on the data set and 1986-last year with complete data entry). To obtain adequate numbers of black adults, NY's four largest cities outside of New York City (NYC) as well as their surrounding county areas 


\section{TABLE 1}

Description of Census Tract Poverty Status and the Association of Tract Poverty Variables with All (Blacks and Whites) Incident Cancer Cases

\begin{tabular}{|c|c|c|c|}
\hline \multirow{2}{*}{$\frac{\text { Poverty Variable }}{\text { Year }}$} & \multicolumn{2}{|c|}{$\begin{array}{l}\text { Census Tract } \\
\text { Propontion }\end{array}$} & \multirow{2}{*}{$\frac{\text { Incident Cancer Cases With } . .}{\text { Pantial Conrelation }}$} \\
\hline & Mean & $S D^{*}$ & \\
\hline \multicolumn{4}{|c|}{ Persons Below $75 \%$ of the Poverty Level } \\
\hline 1980 & 7.7 & 8.1 & \multirow[t]{2}{*}{.385} \\
\hline 1990 & 9.4 & 10.7 & \\
\hline \multicolumn{4}{|c|}{ Persons Below the Poverty Level } \\
\hline 1980 & 11.4 & 11.2 & \multirow[t]{2}{*}{.403} \\
\hline 1990 & 13.1 & 13.8 & \\
\hline \multicolumn{4}{|c|}{ Persons Below $125 \%$ of the Poverty Level } \\
\hline 1980 & 15.6 & 13.5 & \multirow[t]{2}{*}{.410} \\
\hline 1990 & 16.8 & 15.8 & \\
\hline \multicolumn{4}{|c|}{ Persons Below $150 \%$ of the Poventy Level } \\
\hline 1980 & 19.9 & 15.3 & \multirow[t]{2}{*}{.435} \\
\hline 1990 & 20.4 & 17.3 & \\
\hline \multicolumn{4}{|c|}{ Persons Below $200 \%$ of the Poverty Level } \\
\hline 1980 & 29.1 & 17.7 & \multirow[t]{2}{*}{.457} \\
\hline 1990 & 28.6 & 19.3 & \\
\hline
\end{tabular}

Note. Poverty levels are base
hold size (number of dependents). SD = standard deviation.

'Summary case counts (1979-1986) for those cancer sites with significantly greater incidence among blacks: lung, stomach, cervix uteri, and prostate.

Tract population, median age, and gender (proportion female) controlled.

were included (Buffalo, Rochester, Syracuse and Albany). NYC was excluded because the error which intrudes in both numerator and denominator partitions of incidence estimation is at least twice that of Upstate NY. This study's data set was found to be comparable to SEER data on both microscopic confirmation (91.4\%) and death certificate only enumeration $(2.5 \%),{ }^{1416}$ and black and white cases were not found to differ substantively on these scores, respectively $(90.2 \%$ and $91.5 \%)$ and $(1.8 \%$ vs. $2.5 \%)$.

Cases were joined with census tracts ( $n=604$ tracts) through geocodes to extensive socioeconomic data: ${ }^{17-18} 5 \%$ of the cases are missing from this analysis as they lacked :ufficient information for geocoding 


\section{TABLE 2}

The Association of Near Poverty Status-Below 200\% of the Federal Criterion - with Cancer Cumulative Incidence: Age-Standardized Rate Ratios (RRs) Among Black and White Subsamples (1979-1986)

\begin{tabular}{|c|c|c|c|c|c|c|}
\hline \multirow{3}{*}{$\frac{\text { Cancer Site }}{\text { Gender }}$} & \multicolumn{2}{|c|}{ Cases } & \multirow{2}{*}{\multicolumn{2}{|c|}{ Blacks }} & \multirow{2}{*}{\multicolumn{2}{|c|}{ Whites }} \\
\hline & \multicolumn{2}{|c|}{ Low / High Poverty Tracts } & & & & \\
\hline & Black & White & $R R$ & $(95 \% C)^{c}$ & $R R$ & $(95 \% C)^{c}$ \\
\hline \multicolumn{7}{|l|}{ Lung } \\
\hline Female & $70 / 216$ & $3,079 / 416$ & 1.79 & $(1.43,2.25)$ & 1.95 & $(1.76,2.16)$ \\
\hline Male & $167 / 572$ & $6,371 / 961$ & 1.90 & $(1.65,2.19)$ & 2.12 & $(1.98,2.27)$ \\
\hline \multicolumn{7}{|l|}{ Stomach } \\
\hline Female & $15 / 45$ & $603 / 91$ & 1.72 & $(1.10,2.68)$ & 1.99 & $(1.57,2.51)$ \\
\hline Male & $24 / 63$ & $877 / 119$ & 1.46 & $(0.99,2.15)$ & 1.81 & $(1.50,2.19)$ \\
\hline Cervix Uteri ${ }^{d}$ & $19 / 88$ & $563 / 145$ & 2.61 & $(1.73,3.94)$ & 3.83 & $(3.26,4.50)$ \\
\hline Prostate & $111 / 332$ & $4,715 / 535$ & 1.35 & $(1.15,1.58)$ & 1.35 & $(1.23,1.49)$ \\
\hline \multicolumn{7}{|l|}{ Colon } \\
\hline Female & $53 / 160$ & $3,626 / 423$ & 1.62 & $(1.28,2.05)$ & 1.48 & $(1.33,1.65)$ \\
\hline Male & $43 / 143$ & $3,285 / 354$ & 1.71 & $(1.31,2.24)$ & 1.39 & $(1.24,1.55)$ \\
\hline \multicolumn{7}{|l|}{ Rectum } \\
\hline Female & $14 / 46$ & $1,294 / 163$ & 1.92 & $(1.21,3.05)$ & 1.64 & $(1.39,1.94)$ \\
\hline Male & $19 / 58$ & $1,683 / 170$ & 1.59 & $(1.04,2.44)$ & 1.36 & $(1.16,1.60)$ \\
\hline $\begin{array}{l}\text { Breast (Fe- } \\
\text { male) }\end{array}$ & $165 / 341$ & $8,862 / 879$ & 1.28 & $(1.09,1.51)$ & 1.37 & $(1.28,1.47)$ \\
\hline
\end{tabular}

"Standandized rate ratios used the combined (black-white), $1980-1990$ (1982.6 algorithm), adult (25 years of age or older) population of this study's 604 census tracts as the standard: Annual atrisk population of $1,483,809-135,308$ black adults and 1,348,501 whites. Direct adjustment was applied across the following five age strata: $25-44,45-54,55-64,65-74$ and 75 or older.

'Census tract powenty status: low poventy tracts $(n=479)$ are those with less than half $(47.3 \%)$ their population's living below the $200 \%$ federal poverty threshold, whereas, more than half of the residents of high poverty tracts $(n=125)$ are below this criterion: Based upon a poverty quintile score break of 0-3 vs. 4 (i.e., the lowest four quintiles vs. the highest). This criterion cutoff was selected because it allows for adequate numbers of cases, particularly among blacks in low poverty tracts, and it also allows the same poverty exposure criterion to be used for black and white samples.

"Confidence intervals are test-based."

Invasive.

(black and white cases were found to be exactly equivalent on this score).,19 Before proceeding with this study's analysis, the validity of the data set was further assessed by systematically replicating the findings of previous related research with it: 1) comparison of black and white samples on sitespecific cancer incidence and 2) the association of SES (median income) 
with cancer incidence. All of these findings closely resembled those of previous studies.

\section{RESULTS}

\section{Near Poverty Description}

The continuum of poverty descriptors outlined in Table 1 suggest that the prevalence of poverty was stable during the 1980s in Upstate NY: approximately $10 \%$ of the population met the minimum federally established criterion in both 1980 and 1990, while nearly $30 \%$ met a more liberal criterion of two-fold the minimal poverty level. The following example may serve to put this description into a more practical context. In 1980 the minimum poverty threshold for a household with two adults and one child was an annual income of $\$ 6,150$. Even two-fold this minimum standard would make for a difficult life for most families of three. The partial correlations listed in Table 1 are also suggestive of the greater predictive power of more liberal (persons below $200 \%$ of the poverty level $=$ near poverty) versus conservative poverty criteria. No previous study in this field has used the former criterion-this one will. This represents a new variable in the field of social epidemiology, and it seems that by its inclusion of those who are poor as well as those who are near poor, it may be a better predictor of cancer occurrence.

\section{Near Poverty Status and Cancer Incidence}

The cumulative incidence data displayed in Table 2 suggests that the contextual variable of near poverty status is directly associated with the incidence of all of this study's cancer sites. For example, the lung cancer rate ratio of 1.79 found among black females (see the top line of Table 2) is interpretable as follows: the rate of lung cancer among those black women who live in high poverty areas-census tracts where more than $50 \%$ of the residents are poor or near poor, that is, living below $200 \%$ of the federally established poverty threshold-is approximately twice that found among black women living in other, lower poverty areas. It also appears that the strength of the associations are similar among blacks and whites for each site. However, many more blacks $(65.5 \%)$ as compared with whites $(9.7 \%)$ were exposed in 1980 to the attendant health risks of living in high near impoverishment areas, that is, census tracts assigned to the highest quintile on proportion of persons living below $200 \%$ of the poverty level; prevalence ratio $[\mathrm{PR}]=6.75$ (95\% CI: $5.07,3.99)$. This ratio of prevalent expo- 
sure seems to have been maintained throughout the decade-1990, $P R=$ $6.55(4.94,8.65)$.

\section{DISCUSSION}

This study replicates many others in finding that the context or area in which people live is greatly implicated in their health. Specifically, after having defined one-fifth of the census tracts in Upstate NY metropolitan areas as near poor-including the poor as well as those with incomes up to twice the federally established poverty criterion-such impoverishment was found to be directly associated with cancer incidence. Perhaps of most interest, consistent direct poverty-cancer associations were observed across sites, including those with previously known SES-cancer associations (lung, stomach and cervix uteri), those with equivocal ones (prostate, colon and rectum) and even for breast cancer which has been consistently found to be associated with other ecological SES measures in the opposite direction as that found in this study.

This study's cumulative incidence design is potentially limited in a number ways as compared to an incidence density design. Potential problems pertain to numerator data, denominator data and the direction of the hypothesized effect. As for numerators, black cases did not differ substantially from white ones on the proportion which were enumerated on the basis of death certificate information only. Potential denominator problems related to census undercounts are most salient among black males. This study found the rate ratio of prostate cancer due to near impoverishment exposure among blacks to be 1.35. Adjusting for an extreme, though plausible scenario (i.e., an overall undercount of $8.0 \%$ and a four times greater undercount among the high poverty group as compared to the low one), ${ }^{21-22}$ a rate ratio of 1.31 is estimated. As expected, this study's rate ratios among blacks are probably overestimates of true population parameters, but not grossly so. Finally, the alternative directional hypothesis, that is, that cancer occurrence causes SES change, is not thought to be a compelling explanation for the following reasons: information on residence was abstracted at the time of diagnosis and five and ten year mobility patterns have not been found to be associated with site-specific cancer incidence. ${ }^{1,23}$

It ought to be recalled here, that this study's central suggested inference is an ecological one, and does not necessarily compete with any extant individual-level inferences, be they biological, psychological or behavioral. It does imply however, that for each cancer site investigated 
among both blacks and whites, at least one component cause of at least one sufficient cause is contextual, that is, that living in poor to near poor areas is a cancer risk factor. In other words, it is acknowledged that prevalent neighborhood impoverishment and individual lifestyle factors are very much interwoven, and so policies which address the issue of inner-city poverty may not be expected to completely solve the problem of racial group cancer differentials. However, it may be expected that intervention at this macro-level will be centrally important in eventually solving the problem.

This study's findings also point toward ecological action, again, individual-level preventive efforts notwithstanding-political or group action which addresses the needs of at-risk areas is called for. Approximately twothirds of the at-risk census tracts defined by this study are inner city, predominantly black neighborhoods. Most of the remainder (up to 94\%) are directly adjacent to this urban ghetto core. Though it may sound crass in todays oft heard call for color-blind legislation, it may also be instructive for policy makers desiring to build coalitions to note that any preventive efforts directed at the elimination of impoverishment and its consequences are also likely to greatly benefit whites. For example, if a hypothetical direct causal link between poverty and cancer were known and a hypothetical program eliminated $50 \%$ of the problem, even though blacks in a relative sense suffer far more from the experience of poverty, in an absolute sense, three-quarters of the prevented cancer cases would be expected among whites.

\section{REFERENCES}

1. Gorey KM. The Association of Socioeconomic Inequality With Cancer Incidence: An Explanation For Racial Group Cancer Differentials. Doctoral dissertation, State University of New York at Buffalo, 1994, pp 162-167.

2. Gorey KM, Vena JE. Cancer differentials among United States blacks and whites: quantitative estimates of socioeconomic-related risks. I Natl Med Assoc 1994; 86:209-215.

3. Krieger $\mathbf{N}$. Social class and the black/white crossover in the age-specific incidence of breast cancer: a study linking census-derived data to population based registry records. Am J Epidemiol 1990; 131:804-814.

4. Krieger N. Overcoming the absence of socioeconomic data in medical records: validation and application of a census-based methodology. Am J Public Health 1992; 82:703-710.

5. Pappas G. Elucidating the relationship between race, socioeconomic status, and health. Am J Public Health 1994; 84:892-893.

6. Schwartz S. The fallacy of the ecological fallacy: the potential misuse of a concept and the consequences. Am J Public Health 1994; 84:819-824.

7. Susser M. The logic in ecological: I. The logic of analysis. Am J Public Health 1994; 84: 825-829.

8. Rodgers GB. Income and inequality as determinants of mortality: an international cross-sectional analysis. Pop Studies 1979; 33:343-351.

9. Wilkinson RG. Class mortality differentials, income distribution and trends in poverty 1921-1981.J Soc Policy 1989; 18:307-335.

10. Wilkinson RG. Income distribution and life exp:-tancy. $\mathrm{Br}$ Med J 1992; 304:165-168. 
11. Wilkinson RG. Income distribution and mortality: a 'natural' experiment. Sociol Health Illness 1990; 12:391-412.

12. Wilkinson RG. National mortality rates: the impact of inequality. Am J Public Heallh 1992; 82: 1082-1084.

13. McWhorter WP, Schatzin AG, Horm JW, Brown CC. Contribution of socioeconomic status to black/white differences in cancer incidence. Cancer 1989; 63:982-987.

14. Greenberg ER, Colton $T$, Bagne $C$. Measurement of cancer incidence in the United States: sources and use of data. J Natl Cancer Inst 1982; 68:743-750.

15. New York State Department of Health: New York State Cancer Registy. Albany, NY: Author, 1990.

16. Wilson S, Prior $P$, Woodman CBJ. Use of cancer surveillance data for comparative analyses. J Public Health Med 1992; 14:1516.

17. U.S. Bureau of the Census. 1990 Census of Population and Housing-Census Tracts-New Yonk State. Summany Tape File (STT) 3A. Washington, DC: U.S. Government Printing Office, 1992.

18. U.S. Bureau of the Census. 1980 Census of Population and Housing - Census Tracts-Albany, Buffalo, Rochester and Syracuse, NY, Standard Metropolitan Statistical Areas (PHC80-2-61,106,306 and 346). Washington, DC: U.S. Government Printing Office, 1983.

19. Howe HL. Geocoding NY State cancer registry. Am J Public Health 1986; 76:1459-1460.

20. Miettinen OS. Estimability and estimation in case-referent studies. $A m J$ Epidemial 1976; 103:226-235.

21. Fein DJ. Racial and ethnic differences in U.S. census omission rates. Demography 1990; 27: 285302.

22. Wolter KM. Accounting for America's uncounted and miscounted. Science 1991; 253:12-15.

23. Carlo GL, Mettlin CJ. Cancer incidence and trihalomethane concentrations in a public drinking water system. Am J Public Health 1980; 70:523-525. 